\title{
An Application of Collaborative Learning in a CALL Website Construction
}

\author{
Ji Song \\ College English Teaching Department, Dezhou University, Dezhou, China \\ Email: songji126@126.com
}

\begin{abstract}
Rationale and features of collaborative learning and a CALL website construction is discussed to verify the validity of the application of collaborative learning in foreign language teaching. It shows that collaborative learning can effectively promote learners to communicate with others and enhance their abilities to solve problems with the support to group members. Thus it can improve the development of creative thinking and train lifelong learning skills.
\end{abstract}

Index Terms - collaborative learning, CALL, website

Collaborative learning is a kind of learning mode which can make students collaboratively complete an assigned task in a group or team in order to promote learning (Zhang \& Chen, 2005). It reflects modern teaching concept that students are cognitive subjects and embodies modern teaching ideas that students' initiative and creativity should be developed and students' cooperation spirit should be raised.

\section{RATIONALE}

Collaborative learning is grounded in constructivist learning theory and social-cultural theory. Constructivists, like Duffy, Jonassen, Cunningham, believe that learning occurs because an active and self-regulated learner who resolves conflicts between ideas and reflects on theoretical explanations constructs personal knowledge. Besides, sources of meaning are experience and context. There is a real world which we experience; meaning is imposed on the world by use. It is rooted in experience and we should take advantage of new capabilities of new technologies. There is no ultimate, shared reality, but reality is outcome of a constructive process. Goal of instruction is not to assure individuals to know particular things, but construct plausible interpretations of their own.

In the theory, the emphasis is placed on the learner or the student rather than the teacher or the instructor. It is the learner who interacts with objects and events and thereby gains an understanding of the features held by such objects or events. The learner, therefore, constructs one's own conceptualizations and solutions to problems. Learner autonomy and initiative is accepted and encouraged. Constructivists view learning as the result of mental construction. Students learn by fitting new information together with what they already know. People learn best when they actively construct their own understanding.

Constructivist learning theory holds that the development of human cognitive structure is result of the interaction between self-regulating adaptation mechanism of organism and external environment (Zhao \& $\mathrm{Li}, 2000)$. It advocates learning is a process that learners make use of their existing experience, psychological structures and beliefs to construct the internal mental representation on their own initiative. That is, knowledge is obtained not through teacher instruction, but learners' active construction with the help of others (including teachers) and the use of some learning materials in certain circumstances and social-cultural context (Zhao \& Li, 2000). Therefore, context, collaboration, conversation and meaning construction are four elements of constructivist learning theory. Among them, collaboration refers to learners' interaction with teachers and other learners in the process of study and practice.

Social-cultural theory is also called "cultural psychology". It originally referred to a body of ideas proposed by former Soviet psychologists in the socio-cultural movement of the 1930s, in particular, by Vygosky. Lev Vygotsky, the famous psychologist of the former Soviet Union, the founder of social-cultural theory, stressed that all human learning and development are derived from activity. Human's psychology is developed in human activity and in the process of interaction with other people (Zhang, 2006). The development of higher mental function of human beings is all from language-based social communication. People use language to communicate with others to obtain information, then make it internalization and continue to form their cognitions (Zhang, 2006).

In recent years, many new findings have been made on that basis. Contemporary researchers in the socio-cultural tradition, notably Rogoff, Lave, Collins, etc., have put forward new concepts such as cognitive apprenticeship, tele-apprenticeship and distributed cognition. These concepts are sometimes labeled as "Neo-Vygotskyan".

Both Vygotskyan and Neo-Vygotskyan theories have the same primary tenet, that is, human cognition is social in nature. Accordingly, individual mental functions are not emerging privately in one's mind; instead, they are originated in the socio-cultural context as a result of encounters with rituals, conventions, technologies and institutional practices. Therefore, the acquisition of new understanding is made possible only through participation in certain kinds of 
supportive social interactions. We believe that socio-cultural theory is closely related to our present purpose. It can be of direct benefits to our understanding of collaborative learning. Because collaborative learning among students and teachers can help learners bridge the zone of proximal development (Zhang, 2006).

\section{FEATURES OF COLLABORATIVE LEARNING}

Collaborative learning is carried out in a learning group (each typically two to four) and it aims at solving problems through consultation, discussion, and competition, etc. It is external condition for learners to understand problems deeply and obtain higher cognitive ability. The features of collaborative learning are as follows (Hu, 2001):

1. Interaction. Collaborative learning values collaboration between learners, learners and learning group, teachers and learners to promote mutual progress. The interaction in learning process is considered as the source of learning activities.

2. Learning goal. All collaborative learning groups should have a common goal. Students must be taught with collaborative learning skills and be given proper help to make learning activities carried out effectively.

3. Learner's own responsibility. Collaborative learning emphasizes learner's personal responsibility during learning process. To accomplish a common goal, each group member should finish complementary and interrelated tasks to define his own duties.

4. Group target must be hit. Only when all group members achieve their goals can each learner just reach one's own target. Thus collaborative learning can be ended.

\section{MERITS OF COLLABORATIVE LEARNING}

Research on the merits of collaborative learning is well known and convincing. Panitz (1997) concludes thirty-eight merits produced by collaborative learning grounded on the other researchers and practitioners, some of which are as follows:

1. It develops higher level thinking skills.

2. It builds self-esteem in students.

3. It develops oral communication skills.

4. It develops social interaction skills.

5. It enhances self management skills.

6. It creates an environment of active, involved exploratory learning.

7. It establishes an atmosphere of helping and cooperation school-wide.

8. It creates a strong social support system, for it helps to transfer students' social experiences to their involvement in the learning process.

9. Students are taught how to criticize ideas, not people.

What's more, Lunsford (1995) also states that collaboration does the following: aids in problem finding and solving, in learning abstracts, in transfer and assimilation of knowledge; fosters interdisciplinary thinking; leads to sharper thinking and deeper understanding of others; promotes excellence; engages the whole student and encourages active learning; combines reading, talking, writing, and thinking; and allows for practice in synthetic and analytic skills.

To sum up, collaborative learning are of great help for learners to develop higher level thinking skills and acquire meta-cognitive strategies, affective strategies and social strategies, which are the important language learning strategies for effective learners (Oxford,1990). That is to say, collaborative learning at least contributes to learning autonomy and higher learning efficiency.

\section{PRACTICE}

\section{A. Establish Collaborative Learning Group}

In order to make group members complementary in interests, abilities, ways of thinking and behavior methods, learning activities are usually organized in the way of heterogeneous grouping. Firstly group members make free combination according to their interests and then teacher makes appropriate adjustment to make the most of the advantage of all the members. Group members should be two to four.

\section{B. Arrange Learning Content}

Group members were required to build a learning website $A$ Window on CALL as a means of access to CALL (Computer Assisted Language Learning). It includes the making of website logo, scrolling text and images, courseware on CALL information, and critique writing of CALL article, website or CD.

\section{Make a CALL Website}

1. Division of work in each group. In the group of making scrolling text and images, one student should take ten photos of CALL instruction with a digital camera, use Adobe Photoshop software to make initial processing, then search for a short English poem on friendship; another one should surf on the Internet to find HTML and JavaScript source code which can get text or images in a window scrolled left and right or up and down. In groups of producing 
CALL courseware, each group is responsible for making courseware of a chapter from the book Internet for English Teaching. For each chapter, one student should generalize main content, then another person use Microsoft Office PowerPoint software to make a courseware. In addition, each member in each group was asked to write two critiques on CALL, one about a chapter from the book Network-based Language Teaching: Concepts and Practice; the other one about a CALL website or a VCD/DVD. Each article should be at least one thousand words.

2. Collaboration in each group. First of all, relevant group members need to collaborate to make website logo. It should be on the top of webpage with highlighting words $A$ Window on CALL, three images on the background, and three navigation buttons at the bottom of the logo which serve as switch from home page to other web pages. After consultations among group members, the title and subtitle of the logo was decided to use word-art function of Microsoft Office Word software to design (with color transition effect). Background images of the logo were made by powerful and easy-to-learn Adobe Fireworks software. Three images are plant or flower patterns and they should be processed with Adobe Photoshop software. The first image was diluted in an oval shape, and the second one was also done with transparent effect and the third one was embossed with Adobe Fireworks software. Finally Adobe Fireworks was used to integrate title, subtitle and three images. Navigation buttons should be three-dimensional button selected from Microsoft Windows XP operating system, in which two buttons can navigate easily with hyperlink.

Next, the most difficult problem in building the site is to make some text and images scroll. To fulfill this function, HTML and JavaScript were needed to use to compile a small program. Although they aren't large commercial software and it's not difficult for learning and mastering them, it will take a lot of time for learners to study from scratch and it's a hard work for one person to do it. After discussing and consulting computer professionals, group members decided to download HTML and JavaScript source code on the Internet, then modify some parameters by consulting computer books. Each group member was responsible for modifying a part of the code. Eventually, the entire modified one was sorted out and the task was finished.

Then is the problem of using Microsoft Office PowerPoint software to produce CALL courseware. Individuals can produce a simple one, but if they want to achieve effective combination of audio, video, animation, reach the unity of the design and truly arouse learners' enthusiasm in multimedia learning environment, they need to be open for their mind for courseware design. An effective way is to learn from other group members who grasp many skills in it; thereby it's easy to enhance the standard of courseware production.

Finally, that is to integrate the work of all groups and complete the construction of the website. After consultation and discussion among group members, they chose to use Adobe Dreamweaver software to build the framework of the site. At last the website has been finished through the collaboration of all members.

3. Intergroup collaboration. In collaboration with group members it may involve the encounter with a variety of difficulties; however, some issues can be resolved with people's help of wider range, which require collaboration between groups and even outside of groups. Along this line, a computer network is an effective means. The Internet provides learners with the convenience of online synchronous discussion in which learners in different places can make real-time communication and cooperation. By Tencent QQ, Microsoft Network (MSN) learners may achieve hyperspace communication, which can promote learning and reflection deeply and meet the demands of learners' belonging and identification. Moreover, learners at different times and in different locations can consult and discuss by e-mail, BBS and other forms of asynchronous online forum in order to complete the same task of collaborative learning.

\section{Assess Learning Effect}

After making the website, it need assess learning effect of learners. Well-timed and appropriate assessment may not only affirm learners' achievements and maintain interests and motivation of collaborative learning but also find problems. According to feedback, learners can adjust learning strategies to stimulate further collaborative learning motivation and enhance learning levels. To assess learners' learning effect, people can use self-assessment, group members' assessment, assessment outside of group and teacher's assessment.

\section{CONCLUSION}

In contrary to solitary learning, collaborative learning will greatly enhance learners' cognitive development because learners can perform tasks that are currently beyond their reach through the assistance of others. Collaborative learning can also make learners more motivated and confident in learning as they can help each other and co-construct knowledge. Furthermore, it is helpful for students to prepare for future studies outside of formal educational environment.

In the process of constructing a website, non-computer majored learners usually flinch from computer problems. Nevertheless, through collaborative learning, they can not only master the technology of building a personal website, but learn to communicate with other people, raise individual ability to solve problems, promote the development of creative thinking and train lifelong learning skills.

\section{REFERENCES}

[1] Hu Long. (2001). Computer Assisted Language Learning: Multimedia and Networking Applications. Shanghai: Shanghai Foreign Language Education Press. 
[2] Lunsford, A. (1995). Collaboration, Control, and the Idea of a Writing Center, in C. Murphy \& S. Sherwood (Ed.). The St. Martin's Sourcebook for Writing Tutors. New York: St. Martin's Press.

[3] Oxford, R. (1990). Language Learning Strategies: What Every Teacher Should Know. New York: Newbury House.

[4] Panitz, T. (1997). Collaborative Versus Cooperative Learning-A Comparison of the Two Concepts Which Will Help Us Understand the Underlying Nature of Interactive Learning. http://home.capecod.net/ tpanitz/tedsarticlesl/coopdefinition.htm.

[5] Zhang Dianbing, Chen Xuying. (2005). Collaborative Learning: Concepts, Elements and Teaching Strategies. Continue Education Research, 5, 118-119.

[6] Zhang Xuan. (2006). Theoretical Framework of Computer-Mediated Collaborative Language Learning and Affective Issues. CAFLE, 8, 30-35.

[7] Zhao Jianhua, Li Kedong. (2000). Collaborative Learning and Collaborative Learning Mode. China Educational Technology, $10,5-6$.

Ji Song was born in Baoqing, Heilongiiang Province, China in 1972. He received his M.A. degree in applied linguistics from China University of Petroleum, China in 2006.

He is currently a lecturer in College English Teaching Department of Dezhou University, Dezhou, China. His research interests include CALL and comparison between Chinese and western cultures. 